\title{
TTR
}

Traduction, terminologie, re?daction

\section{Yves Gambier and Jorma Tommola, eds. Translation and Knowledge. SSOTT IV. Scandinavian Symposium on Translation Theory. TURKU, 4.-6. 6. 1992 Turku, Grafia Oy/Kansilkuva: Maria Kald, 1993, 417 p.}

\section{Paul Bandia}

Volume 7, numéro 2, 2e semestre 1994

Traduire les sociolectes

URI : https://id.erudit.org/iderudit/037187ar

DOI : https://doi.org/10.7202/037187ar

Aller au sommaire du numéro

Éditeur(s)

Association canadienne de traductologie

ISSN

0835-8443 (imprimé)

1708-2188 (numérique)

Découvrir la revue

Citer ce compte rendu

Bandia, P. (1994). Compte rendu de [Yves Gambier and Jorma Tommola, eds. Translation and Knowledge. SSOTT IV. Scandinavian Symposium on Translation Theory. TURKU, 4.-6. 6. 1992 Turku, Grafia Oy/Kansikuva: Maria Kald, 1993, 417 p.] TTR, 7(2), 213-219. https://doi.org/10.7202/037187ar d'utilisation que vous pouvez consulter en ligne.

https://apropos.erudit.org/fr/usagers/politique-dutilisation/ 


\section{Catherine Mavrikakis Université Concordia}

Yves Gambier and Jorma Tommola, eds. Translation and Knowledge. SSOTT IV. Scandinavian Symposium on Translation Theory. TURKU, 4. -6. 6. 1992 Turku, Grafia Oy/Kansikuva: Maria Kald, 1993, 417 p.

This book is a collection of papers presented at the Fourth Scandinavian Symposium on Translation Theory (SSOTT IV) organized by Turku University on 2-4 June, 1992. The papers cover a wide range of traditions and approaches in Translation Studies (TS). Some papers are based on individual research programmes, and many of the participants are from countries outside the Scandinavian region.

In an attempt to establish some order among this great variety of papers, the editors partition the contributions into four thematic groups: (1) History/Epistemology, (2) Background knowledge and Cross-linguistic Communication, (3) Processes and Strategies, (4) Genres and Conventions. Of the four thematic groups only the papers in Part I seem to be related in some logical way. This might explain why there are only four contributions in this section out of twenty-nine papers published in the book. The other papers are split up into three thematic groups under some kind of partition. One can only commend the editors for trying to make some sense out of this "babel" which is quite characteristic of research in TS. It may also be indicative of how "democratic" and tolerant we have become as we face great odds in our quest for a comprehensive translation theory. Indeed, the editors did their best to arrange the papers, as they put it, "in a sufficiently 
meaningful way" (see foreword). After all, they point out that the topic of the symposium "Translation and Knowledge" was deliberately chosen to allow for "a multiplicity of approaches."

The papers in Part I are linked by a common thread: the history of translation. The authors take translation historians to task for limiting their enterprise to a mere collection of data without any profound reflection upon the goals and consequences of a history of translation.

José LAMBERT sets the tone with a critical and insightful look at History and Historiography in relation to TS. His paper takes off on a positive note extolling the good fortune of translation and TS in the face of declining economic interests in the Humanities in general. Apparently, the profession and discipline have become so fashionable that they can still find funds where better-established disciplines cannot. Lambert then tackles the main subject of his paper. He opens the discussion with a witty statement that there is "no genuine, theoryneutral road into history; no genuine, a-historical road into theory"; a statement which he rightly remarks is "itself a nice theory" (p. 3). In his view, although there is a great amount of historical material to be discovered, recorded and explained in a historiography, one has to distinguish between the object of study and the discourse on the object of study. It is not enough to gather historical material in a cumulative, atomistic and normative way, without any clear conceptualization of historiography. A historiography for translation should be defined and should not be simply borrowed from the historiographical schemes of other disciplines, especially the positivistic ones with no theoretical or methodological background. If translation has to be studied as communication, its frame of reference has to extend beyond strict translational ones. Hence, the history of translation should be related to the real world where translation is viewed both in terms of theory and practice. The aim of history and historiography also has to be defined. According to Lambert, the study of translation is not taken seriously within the Humanities because historical investigations on translation are often limited to a mere accumulation of data. Translation study "seems to function for its own sake, as a very sophisticated kind of research, and not as a specialization that provides insight into the basic strategies of culture" (p. 14). 
In Lambert's view, an explicit programme for historical research could reveal the Eurocentric bias of contemporary translation theory. The latter is heavily influenced by Western institutionalization of languages, societies and cultures, to the exclusion of the understanding of linguistic realities in non-Western contexts. Societies are always overlapping and always dynamic. As an interdisciplinary activity, translation has the potential to reveal the deeper roots of society and culture.

Anthony PYM's paper proposes a "negotiating theory as an approach to translation history" (p. 27). His paper is very lively and pleasant to read as he uses soccer metaphors which are likely to drive home his message quite easily among soccer amateurs. The comparison of a line referee and the translator is most revealing. According to Pym, "the line referee has to be able to look in two directions and at two (or three) players at once, just as the translation analyst should be able to consider two cultures and two writers (plus at least one potential reader) at once" (p. 27). However, the similarities between soccer and translation stop there. As he sees it, today at least in soccer the human referee has wide-angle camera lenses to perceive mistakes, whereas in translation there is no theoretical frame wide enough to take in both moments at once. Translation studies are based either on the traditional approach which places emphasis on the sending side (source-text) or on the more "contemporary systemic and purpose-based approaches" which "tend to focus on the target side, analyzing translation as new texts in their own right" (p. 27). Pym thus proposes a translational version of the wide-angle lens, or at least sufficient conceptual distance as a means to reconcile the two approaches. In this regard, he proposes a regime theory which "focuses on negotiating procedures themselves as a space organized by its own inter-systemic principles; instead of analyzing confrontations and transfers between interdependent states" (p. 28). A regime theory will lead to the formulation of translation regimes. The latter will be based on the networks by which objects move from one culture to another and will thus represent the general rules guiding translation activity within transfer networks. Such a theory will assume the mutual presence of translators and authors thus hypothetically eliminating the material distance involved. A sociological underpinning to the idea of mutual presence is the notion of interculturality which holds that translators are by definition intercultural subjects. Hence, the 
translator's behaviour can be explained in terms of shared intercultural regimes rather than individual cultural systems. Like the line referee's wide-angle lenses, the regime theory can be used to look in two directions at once, at the sending side and at the target side of translation. Pym goes on to illustrate his point by discussing Nicholas Round's analysis of a 1455 translation of Plato's Phaedo into Castilian by Pero Díaz de Toledo, translated from Leonardo Bruni's previous Latin version.

Jean-René LADMIRAL begins his paper "Towards a Philosophy of Translation" by pointing out the main obstacle to finding a comprehensive theory of translation which should be obvious to any serious scholar in this field, namely "that social sciences research is not universal" but rather "rooted in cultural and even national traditions and modes of thinking" (p. 41). He thus commends the organizers of this congress for "allowing some reception of French-speaking or rather writing (and written) TS" (p. 41). By this he joins Lambert and Pym in deploring the Eurocentric bias characteristic of TS today.

Ladmiral's main intent is to question the validity of approaching TS in terms of the traditional dichotomy between literalism (the "sourcier" approach) and semanticism (the approach of the "cibliste"). What Ladmiral would like to have instead of this dichotomy is a literary model of translation theory. After all, literary translation is still the most interesting for translation theorists, and it does not in any way overlook the realities of professional translation and translation training. Moreover, as written texts, translations do have at least some literary dimension. Such a literary model for translation theory will be based on developing a theory of literary genres and its implications for translation. After pointing out the limits of modern linguistics in providing clear and assured principles for defining a science of translation, he proposes a philosophical model of translation based on an "unconsciousness of translation" (p. 43).

Ladmiral wonders why there is so much violence in certain debates about translation, particularly between the "sourciers" and the "ciblistes." He tries to cast the polemic in some historical terms, but fails to acknowledge how much he contributes to this "violence" by being an avowed "cibliste." His belief that one cannot develop 
"philosophical insights in a foreign language, because language is not only a garment but concerns the very substance of thought itself" (p. 46) reminds one of the Sapir/Whorf hypothesis with its clear preference for so-called native speakers with respect to language use. This smacks of linguistic nationalism and is reminiscent of the kind of reductionist attitude Ladmiral criticizes at the beginning of the paper when he praises the organizers of this largely "nordic" congress for "allowing some reception of some French-speaking...TS." As if aware of the storm that might gather around his view, he states that Nouss has accused him of being too language-bound for an avowed "cibliste," and quickly points to the experiences of self-translation by writers and philosophers as an alibi. The experiences allegedly show that an author does not compose the same text or develop the same system in a second language. Ladmiral clearly rejects the view that literary translation should be "sourcier" oriented, and thus takes Berman to task for stating that literary translation should be literal translation. As he puts it, "translation is not mere linguistic mimicry" (p. 48). "Sourcerian translation" can only have an evaluative or pedagogical or epistemological function. In this regard, a philosophical model of TS can have some fallout for "the applied level of translation teaching and even for foreign language teaching" (p. 49).

Inspired by a quote from Freud's Lectures on Psycho-Analysis, Alexis NOUSS has some good news for translators: that they are not hysterical and that the ideal form of translation does not have to do with hysteria. On this encouraging note, he goes on to tell us why an hermeneutical point of view is good for translation. Within this framework, comprehension is much more easily achieved in the case of a foreign language than a familiar one, which implies that translation between languages would seem less difficult than understanding within the same language. And this leads to a paradox whereby "strangeness" is more perceptible and more easily located in a message (Freud's notion of uncanny). It follows from this that if source text and target text are completely heterogeneous, foreign to each other, their translation is only possible through a "conversion of code" (p. 54). Yet translation is more like intralingual comprehension. It involves a range of factors such as the translation subject and the translator's experience and history, as one can only translate in relation to one's own situation. Like Gadamer, Nouss is not satisfied with the mere historical/cultural 
knowledge of the circumstances under which a target text is created. Indeed, as self-understanding is a part of the process of understanding, it is also a part of the translation process. Furthermore, Nouss rehashes the question of whether translation is an art or a science, and chastises contemporary TS for adopting a mainly epistemological framework inspired by linguistics with an obvious positivist bias. He believes it is time to integrate a hermeneutical approach to the process of translation, given the importance of self-understanding in this matter. Hermeneutics is therefore a viable alternative to the divisive source/target, "sourcier"/"cibliste" dichotomy. Nouss seems to be looking for a healthy compromise. With hermeneutics there is a merger of the world of the text to be translated and the world of the translator, a kind of merging of horizons of a history in constant flux (Gadamer). Given a true hermeneutics of translation, the translator is never fixed within one horizon. $\mathrm{S} / \mathrm{he}$ is rather in a kind of nomadic horizon where $\mathrm{s} / \mathrm{he}$ is neither sourcer nor targeter. History, and not language, is the "being" of translation, and "the History of translation is the translation of history" (p. 62).

Section II of this book contains a series of papers which are for the most part the results of individual, isolated research programmes, which are however related in that they are mostly about "oral" translation or interpretation. Daniel GILE's paper clearly demarcates translation from interpretation and proposes a Gravitational model perspective.Cecilia WADENSJÖ's contribution deals with an interesting type of interpreting, namely dialogue interpreting, which reminds one of the increasingly popular "community interpreting". D. J. FOURIE's paper, which does not seem to belong to this section, gives us an insight into what is described as a Third World perspective on translation. The paper grapples with the question of how to translate First World technical-scientific terminology into languages in the Third World, particularly African languages. The rest of the contributions in this section deal with ways of defining knowledge and meaning in translation, and suggest ways and frameworks to deal with the two concepts.

Part III is about processes and strategies in translation. The contributions range from translation process analysis to the question of untranslatability, the translation of grammar and a cognitive perspective 
on semantic change in translation. Rita OITTINEN's paper on dialogue and translation and Helle VRONNING DAM's paper on text condensing in consecutive interpreting would seem to belong to part II with the other papers on "oral" translation.

Part IV which is entitled "Genres and Conventions" is a hotchpotch of unrelated but quite insightful papers. A factor common to all the papers in this section is that they deal with text-types and texttype conventions. The texts range from Russian to Finnish, Canadian and Arabic. Kerstin EKSELL's "Translation of Modern Arabic Fiction" is a good example of the difficulty involved in translating from nonEuropean languages into Western languages. Gunilla ANDERMAN's "Translation and Speech Acts" is a clear example of how interactional (socio-)linguistics is contributing to TS. This paper is appropriately followed by Cornelia ILIE's "On the Translatability of Rhetorical Questions" which is another illustration of how the study of language in use (pragma-linguistics) has become important for TS.

On the whole the book is a good reference tool for research on current trends in TS. There are a few typographical errors and some papers seem to have been initially thought out in the authors' first language and then written in an English which reveals some of the shortcomings of translation raised in the book - Ladmiral might after all have a point about the impossibility of expressing one's thoughts with as much impact in a second language! However, these weaknesses notwithstanding, the book is a gold mine of thought-provoking papers from a great variety of backgrounds and regions of the world.

Paul Bandia Concordia University 